\title{
El Covid-19 y su incidencia en la situación económico financiera en la cooperación agraria peruana Jaén en el año 2020
}

\author{
Raizza Jeanina D’karla Mija Vásquez \\ rjd_10_7@hotmail.com \\ Celia Quispe Gonzáles \\ Celia.qg.92@gmail.com \\ Universidad César Vallejo \\ Moyobamba- Perú
}

\section{RESUMEN}

Objetivo: Determinar la incidencia del COVID-19 en la situación económico financiera en la Cooperación Agraria Peruana Jaén 2020. Siendo el tipo de estudio aplicada, nivel descriptivo y diseño no experimental; en el cual se ha tomado a 5 personas como población y muestra, fueron encuestados mediante un cuestionario de preguntas; por lo tanto, el trabajo concluye que, el Covid - 19 incide en la situación económico financiera, situación contrastada por una significancia de 0,545 y un coeficiente de correlación de Pearson de 0,366 la cual es positiva y baja. Asimismo, las medidas gubernamentales sociales inciden en la situación económico financiera, situación que ha sido contrastada por una significancia de 0,715 y un coeficiente de correlación de Pearson de 0,225 la cual es positiva y baja. Además, las medidas gubernamentales económicas inciden en la situación económico financiera, lo cual ha sido contrastada por una significancia de 0,312 y un coeficiente de correlación de Pearson de 0,573 la cual es positiva y moderada. Por último, las ratios financieras inciden en la situación económico financiera, contrastada por una significancia de 0,000 y corroborada por un coeficiente de correlación de Pearson de 1,000 la cual es positiva grande y perfecta.

Palabras clave: covid - 19; situación económico financiera; medidas gubernamentales. 


\title{
Covid-19 and its impact on the economic-financial situation in the peruvian agrarian cooperation Jaén in the year 2020
}

\begin{abstract}
Objective: To determine the incidence of Covid - 19 in the financial economic situation in the Peruvian Agricultural Cooperation Jaén 2020; being the type of applied study, descriptive level and non-experimental design; in which 5 people have been taken as population and sample, were surveyed by means of a questionnaire of questions; therefore, the work concludes that, the covid - 19 affects the financial economic situation, situation contrasted by a significance of 0,545 and a Pearson correlation coefficient of 0,366 which is positive and low. Likewise, the government's social measures have an impact on the economic and financial situation, a situation that has been contrasted by a significance of 0,715 and a Pearson correlation coefficient of 0,225 which is positive and low. In addition, government economic measures affect the financial economic situation, which has been contrasted by a significance of 0,312 and a Pearson correlation coefficient of 0,573 which is positive and moderate. Finally, the financial ratios affect the financial economic situation, contrasted by a significance of 0,000 and corroborated by a Pearson correlation coefficient of 1,000 which is positive great and perfect.
\end{abstract}

Keywords: covid - 19, economic and financial situation; government measures.

Artículo recibido: 10 Setiembre. 2021 Aceptado para publicación: 15 Octubre. 2021

Correspondencia: rjd_10_7@ hotmail.com

Conflictos de Interés: Ninguna que declarar 


\section{INTRODUCCIÓN}

La Pandemia mundial Covid - 19 ha ocasionado un gran daño económico en el mundo y en el Perú, generando un futuro incierto. En Chile, Colombia, Ecuador, México y Perú, se implementaron medidas gubernamentales, porque el Covid - 19 destruyó en Chile el empleo logrado en 10 años y el PBI del 2020 sería de -4.9\%, en Colombia el desempleo alcanzó el 19.8\%, en Ecuador, el PBI de 2020 sería de -6\%, en México, el PBI del 2020 sería de $-10 \%$ y en el Perú sería de $-15 \%$ en el 2020. (Universidad de Lima, 2020).

El Covid - 19, representa una conmoción mundial, para la compra y venta del café, y constituye un gran reto para los que producen y para el que trabaja en la agricultura. El Covid - 19 repercutirá en la alimentación y situación económica de la gran mayoría de productores de café a nivel mundial, porque son pequeños agricultores que tienen muy poca producción en países pobres sin preparación para enfrentar una pandemia tan grande, y que se han agrupado en Asociaciones y Cooperativas para mejorar sus ingresos económicos. (Hernández et al, 2020)

A nivel nacional, la Junta Nacional del Café al año 2020, cuenta con 47 miembros, entre Asociaciones y Cooperativas Agrarias Cafetaleras afiliadas, las que se encargan de realizar operaciones de comercialización y exportación de café a los diferentes países del mundo. (Junta Nacional del Café, 2020); y a la vez, informa que por cuatro años consecutivos la caficultura peruana registrará pérdidas debido a los bajos precios del mercado internacional, la escasa mano de obra y la inestabilidad del clima en las zonas cafetaleras. (Junta Nacional del Café,2019); acción que se ve agudizada por el Covid 19, en las cuales el Poder Ejecutivo tuvo dictar muchas regulaciones sanitarias, para el sector social y económico que han impactado en la situación financiera empresarial.

A nivel local el sector cafetalero no ha sido ajeno a la problemática, pues la Cooperación Agraria Peruana de Jaén, dedicada al cultivo de café y afines y crianza de ganado vacuno como actividad principal y Clasificación Industrial Internacional Uniforme (CIIU) 0150 del Instituto Nacional de Estadística e Informática (INEI) y como actividad secundaria 1-4773: Venta al por menor de otros productos nuevos en comercios especializados, y actividad secundaria 2-0161: Actividades de apoyo a la agricultura.

Como persona jurídica se ha visto afectada por las distintas medidas sanitarias y sociales emitidas por el gobierno, por declarar emergencia nacional, y también por las medidas gubernamentales económicas, como el otorgamiento de crédito con el Programa 
Reactiva Perú, el Beneficio del Fondo empresarial FAE - MYPE, la reprogramación de créditos, el trabajo remoto, la licencia con goce de haber compensable, el Subsidio del $35 \%$ y la Suspensión Perfecta de labores que afectan la Liquidez, solvencia y rentabilidad de la asociación.

La presente investigación beneficiará al gerente General, pues le ayudará a conocer y aplicar cada una de las medidas sociales, sanitarias y económicas adoptadas por el gobierno central y evaluar su incidencia en la situación económico financiera en la asociación, especialmente en lo referente a la liquidez, solvencia y rentabilidad. Asimismo, la investigación tiene un valor teórico, pues al investigar sobre ambas variables de estudio, facilitará percibir la incidencia que tienen una sobre la otra, lo cual contribuirá a tomar decisiones correctas en el futuro, a su vez el estudio servirá como fuente de información para otras investigaciones de similar característica.

Por otro lado, ayudará a cumplir cada norma dada por el gobierno, como también permitirá evaluar el grado de liquidez, solvencia y rentabilidad, minimizando cualquier eventualidad normativa. Tiene relevancia social, ya que incentivará a los asociados a participar activamente en el acopio y comercialización del café para mejorar sus ingresos económicos familiares por medio de mejores precios. Finalmente tiene utilidad metodológica, pues la realización del presente estudio se desarrollará a través del instrumento empleado, el cual es el cuestionario, el mismo que generará una noción válida y confiable respecto al conocimiento, a su vez los métodos estadísticos empleados facilitarán la recolección y procesamiento de datos.

\section{A. Trabajos previos}

Medina, A. (2021). Auditoría de gestión durante la emergencia sanitaria por el Covid - 19 en el período marzo - junio de 2020 en la asesoría contable MSN Corp." Universidad Técnica de Ambato - Ecuador. Siendo una investigación básica, con nivel descriptivo, diseño no experimental, la población y muestra se constituyó por 6 trabajadores de MSN Corp., aplicándoseles como técnica e instrumento, la entrevista y el cuestionario respectivamente. Concluyó que, en la pandemia del Covid - 19, no se tiene vías de comunicación estupendas para la realización del teletrabajo, también no cuenta con una reglamentación interna, repercutiendo en forma significativa en la productividad del trabajador, también no se han efectuado evaluaciones periódicas tanto a los trabajadores de la empresa como a sus evoluciones laborales dando como respuesta 
una productividad insuficiente. Asimismo, Molina, O. (2021) "Covid-19 y su impacto en establecimientos de alojamiento en la cabecera Cantonal Jipijapa". (Tesis de licenciatura). Universidad de Sur de Manabí- Ecuador. Tuvo como objetivo analizar el impacto que ocasionó la Covid-19 en establecimientos de alojamiento en la cabecera cantonal Jipijapa. Fue una investigación de tipo mixta cuantitativa-cualitativa, de nivel descriptivo, bibliográfica; la población la conformaron 9 establecimientos y la muestra 12 trabajadores, se empleó como técnica la encuesta. Concluyó que el sector hotelero de Jipijapa fue vulnerable ante la crisis, en el aspecto económico, dos establecimientos suspendieron la prestación de sus servicios, se ajustó el salario temporalmente en los colaboradores y cancelación de contrato. En las afectaciones sociales, se evidenció nuevas formas de planificación financiera priorizando los gastos imprescindibles, estado de temor por ser desvinculados de sus labores y miedo de contraer la enfermedad, lo cual ha provocado inestabilidad en la vida personal de los colaboradores.

Por otra parte, Santana, P. (2021) "Incidencia financiera de la pandemia Covid - 19 en la gestión de mercaderías de la empresa TAY FU S.A. al 31 de diciembre de 2020”. (Tesis de Maestría) Universidad Politécnica Salesiana, Quito - Ecuador. El objetivo fue estudiar los resultados financieros que la pandemia COVID-19 ocasionó en los productos de la Compañía Tay Fu S.A. al 31 de diciembre de 2020. Se usó una metodología descriptiva, analítica y comparativa con un enfoque cualitativo, se utilizó como técnica la entrevista a una población y muestra de 3 trabajadores conformados por el Gerente General, la Contadora General, y el jefe de Mercaderías; y como instrumento un cuestionario de control interno. Concluyó que el Covid - 19 tuvo efectos en el inventario, pues en el 2020 rotó 2,99 veces y 2.69 veces en el 2019; la liquidez en el 2020 fue de 1,86 veces y en el 2019 de 1,65 veces, la prueba ácida, fue de 1,27 veces en el 2020, y de 0,89 veces en el 2019; la rentabilidad, en el 2020 fue de 16\%, frente al 2019 del 6\%; el endeudamiento, en el 2020, fue de 89\% frente al año 2019 del 95\%; por lo que los indicadores financieros empleados en la empresa en el 2020, pese a las limitaciones económicas por pandemia, presenta mejores resultados que en el 2019.

Jaramillo, J. y Ramírez, Y. (2020).” Analizar los Impactos Económicos sobre los Ingresos de los Estados Financieros durante la Pandemia en la Empresa Calzado Rómulo Cedeño de la Ciudad de Neiva Año 2018 al 2020”. (Tesis de Licenciatura). Universidad Antonio Nariño. Huila - Colombia. Tuvo como objetivo determinar los 
impactos económicos sobre los ingresos de los estados financieros durante la pandemia en la compañía calzado Rómulo Cedeño de la ciudad de Neiva año 2018 al 2020. Fue una investigación cuantitativa, de nivel descriptivo, con una población y muestra de 6 trabajadores, se empleó como técnicas la entrevista y el análisis documental. Concluyó que las ventas disminuyeron a $9 \%$ con respecto al año anterior, los gastos operaciones aumentaron con respecto a las ventas ya que siguió sosteniendo la planilla del personal durante el cierre obligatorio, los ingresos aumentaron un $64 \%$ por el subsidio al empleo formal (PAEF) para pagar planillas, y su utilidad en el 2020 fue de 3\%. Claro, M. y García, V. (2021). "Análisis del comportamiento de los agentes económicos en ahorro, inversión y consumo frente al COVID-19 en la Bahía de la ciudad de Guayaquil, periodo 2019-2020". (Tesis de licenciatura) Universidad de Guayaquil- Ecuador. Tuvieron como objetivo exponer la influencia del COVID-19 en el comportamiento de los agentes económicos de la Bahía de la ciudad de Guayaquil. Fue de enfoque cuantitativo, con alcance exploratorio, de nivel descriptivo, con una población de dos asociaciones independientes con 590 comerciantes y una muestra de 335 comerciantes. Concluyeron que tras la incertidumbre experimentada por la pandemia, los comerciantes señalaron que no tiene planes de invertir, por la inseguridad de una nueva cuarentena, más bien priorizan el ahorro, ahora con mucha más frecuencia, pero en menor cantidad por la falta de ingresos que antes de la pandemia y sus ahorros aumentaron por precaución.

Pérez, R. y Tapia, E. (2020) “Actividades económicas frente al Covid-19 y su incidencia en la rentabilidad de la Cooperativa Agraria Allima Cacao, Chazuta 2020”. (Tesis de licenciatura). Universidad César Vallejo Tarapoto - Perú. Cuyo objetivo era establecer la Influencia de las actividades económicas frente al Covid-19 en la rentabilidad de la Cooperativa Agraria Allima Cacao, Chazuta 2020. Investigación aplicada, cuantitativa, de nivel descriptiva, no experimental correlacional, con una población y muestra de 9 empleados a quienes se les aplicó un cuestionario. Concluyeron que, las actividades económicas frente al Covid-19 influyen sobre modo importante en la utilidad de la Cooperativa Agraria Allima Cacao, Chazuta 2020, a un grado del 95\% de confiabilidad. Los efectos de la prueba estadística Chi-cuadrado de Pearson donde valor de significancia fue 0,003 , estando menor al valor esperado, con un coeficiente de contingencia de 0.603. Lo que dispone que las actividades económicas repercute de forma negativo en la productividad, porque se demostró que no se efectuaron 
adquisiciones ni entregas en mayores cantidades, ni siquiera realizaron envíos fuera del país, etc, y por eso los índices de rentabilidad dieron negativo. También, Ríos, Y. y Rodríguez, O. (2020). "La pandemia de la covid-19 y su afección en la situación económica financiera del Hotel Bracamonte, distrito de Huanchaco 2020”. (Tesis de licenciatura). Universidad César Vallejo Trujillo - Perú. Se propuso precisar cómo afectó la pandemia de la covid-19 en la situación económica financiera del Hotel Bracamonte, distrito de Huanchaco - Trujillo 2020; de tipo aplicada, no experimental, transversal, descriptivo, la población la conforma el hotel y la muestra 3 trabajadores, se aplicó como instrumento el cuestionario y la guía de análisis documental. Concluyó que la pandemia covid-19 contó con una afección dura en la situación económica financiera del Hotel Bracamonte, porque obtuvo una pérdida muy grande en el 2020 frente al 2019, la rentabilidad sobre inversión dispuso una varianza del $-98.11 \%$, no hubo regreso, por lo perdió más de lo que se invirtió, el Estado de situación financiera y de resultados indica que el gasto fue mucho mayor que la ganancia en este periodo 2020. En cuanto a Chapoñan, V. y Rivera, K. (2020). "Medidas económicas del gobierno por el Covid 19 y su impacto en la situación económica - financiera de la empresa "Transportes Lamar S.A.C. I semestre 2020, Nuevo Chimbote”, (Tesis de licenciatura). Universidad César Vallejo. Siendo cualitativa, aplicada, diseño interpretativo, como instrumentos el cuestionario y la guía de análisis documental. Concluyeron que las medidas dadas por el estado ha tenido consecuencias en la situación económica financiera de la empresa, son el FAE-MYPE y Reactiva Perú, también en la liquidez y rentabilidad de la empresa, porque no se recibió el apoyo financiero para seguir con los pagos, por lo que la compañía no pueda con sus responsabilidades a corto tiempo. Por su parte, Condori, E. y Delgado, E. (2020). "Pandemia por Covid-19 y su impacto en la liquidez de las empresas del sector turismo, Perú, 2020". (Tesis de licenciatura). Universidad César Vallejo. Se propuso determinar el impacto de la pandemia por Covid-19 en la liquidez de las empresas del sector turismo de Perú en el 2020, con una investigación aplicada, no experimental, nivel explicativo, como población y muestra 3 empresas, y como instrumento la guía de análisis documental. Concluyeron que la pandemia por Covid-19 disminuyó la liquidez en un $31 \%$ en las empresas del sector turismo del Perú en el 2020, porque bajaron su nivel de ingresos por ventas debido a la suspensión de sus servicios y por pagar sus deudas a corto plazo pese a la crisis. 
Asimismo, Mesa, L. y Rengifo, U. (2020) "La planeación y la necesidad de la liquidez en tiempos de Post Covid - 19 en el rubro restaurantes ciudad de Pucallpa 2020". (Tesis de licenciatura). Universidad Nacional de Ucayali Pucallpa - Perú. Su objetivo era estudiar la planificación y su vínculo con la escasez de liquidez en período de post Covid19 en el rubro restaurantes ciudad de Pucallpa 2020, investigación básica, descriptiva correlacional, diseño no experimental, transversal, con una población 77 representantes, y una muestra de 70 representantes, como instrumentos el cuestionario y como técnica la encuesta. Concluyeron que existe un vínculo importante de la planificación post Covid-19 teniendo en cuenta el panorama y los peligros globales frente a la obligación de avance de la liquidez en el período de un año del plan de reactivación de la fase 3 en el sector restaurantes ciudad de Pucallpa 2020, el 54,29\% señala de muy conveniente que la planeación post Covid-19 considerando los escenarios y riesgos globales ante la necesidad de mejora de la liquidez en el corto plazo del plan de reactivación de la fase 3 en el rubro restaurantes ciudad de Pucallpa 2020, contra un $8,57 \%$ que señala nada conveniente.

\section{B. Teorías relacionadas al tema}

Pan, et al (2020), define al Covid - 19, “como una enfermedad respiratoria infecciosa y contagiosa que lo produce el virus SARS - CoV - 2"; por otro lado, El 30 de enero de 2020, la Organización Mundial de la Salud (OMS), declaró al Covid - 19 como una epidemia y una emergencia de salud pública de alcance mundial y el 11 de marzo de 2020 la declaró como pandemia. (OPS y OMS, 2020). Por lo que, Khan, et al (2021); Pinilla, et al (2021); Bahnareanu (2020) sostienen que los costos del Covid - 19 a corto plazo son gran pérdida de vidas humanas, victimas con problemas posteriores de salud, afectación del consumo y la producción, como también costos a largo plazo como actividad económica del país distorsionada, disminución de la productividad y el empleo, ingresos, insolvencia y quiebra de empresas. Al 8 de mayo de 2020, el Covid - 19, infectó a 3.938.064 personas y mató a 276.863 mundialmente, para controlar su expansión, los países han cerrado sus fronteras, han declarado cuarentena para sus pobladores, controlan el transporte público y privado, cierran mercados, pero no a la agricultura por ser una actividad esencial en la vida de las personas y que solo hubieron históricamente, dos episodios similares, la Muerte Negra de 1347 a 1351 y la Gripe Española de 1918 a 1919. (Pan, et al 2020, Ruiz, et al 2021). Varona y Gonzales (2020) señalan que el Covid - 19 
en el Perú, ha tenido un doble impacto, por un lado, la disminución del precio en las materias primas, exportaciones limitadas y por otra pérdida de empleo, no hay turismo y no existe financiamiento externo. A decir de Clemente, et al (2021) estamos enfrentando uno de los mayores desafíos de intervención social, que necesita respuestas rápidas, efectivas del sector público, el sector privado y del gobierno para servir a una población con muchas necesidades urgentes de solucionar.

En el Perú, el 11 de marzo de 2020 se dictaminó el Decreto Supremo Nº08-2020-SA, a través del cual se determina el estado de emergencia sanitaria nacional, por tres meses, disponiéndose medidas de prevención y de control sanitario para evitar la propagación del COVID-19 en puertos, aeropuertos y puertos de entrada terrestres, centros educativos, espacios públicos y privados, transporte y centros de labores; y a través del Decreto Supremo No 044-2020-PCM, se dictamina el Estado de Emergencia nacional por 15 días y disponiéndose cuarentena obligatoria, por la rápida propagación del Covid - 19; se garantizan el buen abastecimiento de alimento, medicina, servicios básicos, gasolina y otros; restringiéndose el acceso del público a todo tipo de locales donde se concentren grandes grupos de personas, a excepción de centros comerciales que vendan al por menor, alimentos y productos de primera necesidad, medicinas, presten servicios médicos, ópticos, ortopédicos y petróleo y gasolina.

Dentro de las medidas económicas gubernamentales adoptadas, se encuentra el Decreto de Urgencia $\mathrm{N}^{\circ} 029$ - 20 con el que se autoriza el financiamiento a las Mypes, creándose para ello el Fondo de Apoyo Empresarial (FAE _ MYPE), para garantizar créditos, reestructuraciones y refinanciamiento de deudas a todas las Mype de producción, turismo, comercio y servicios, que necesiten capital de trabajo, o tengan un crédito vigente; y deseen reprogramarlos o refinanciarlos con un plazo máximo de 36 meses y un periodo de gracia de seis meses. (El Peruano, 2020).

Otra de las medidas económicas gubernamentales fue crear el Programa de Garantías del Gobierno Nacional "Reactiva Perú”, según el Decreto Legislativo 1455, y modificado con Decreto Legislativo 1457, para cubrir las necesidades de liquides de las empresas por el Covid - 19 mediante el acceso al crédito de capital de trabajo, le puedan pagar a sus trabajadores, y proveedores. El Gobierno garantiza al pequeño, mediano o gran empresario un crédito que representa tres meses de ventas promedio mensual del 2019 hasta por un monto máximo de s/ 10 millones de soles, y a las microempresas el 
equivalente a dos meses promedio de deuda mensual hasta por un monto máximo de s/ 40 000, en un plazo de 36 mes incluido 12 meses de período de gracia. (Ministerio de Economía y Finanzas, 2020).

Por otra parte, en los art. 14-16 del Decreto de Urgencia Nº 033-2020 se aprobó por parte del Estado subsidiar con el 35\% a los trabajadores que ganen un sueldo menor o igual a s/ 1500.00 y que estén en la planilla de empresas del sector privado, excluyendo a empleadores comprendidos en la ley $\mathrm{N}^{\mathrm{o}} 30737$, con deudas tributarias en cobranza coactiva al 31 de diciembre de 2019 mayores a 5 UIT, el trabajador debe estar registrado en la Plame de enero 2020, presentado en febrero del mismo año y que el T registro no indique fecha de fin o sea anterior al 15 de marzo de 2020.

El análisis financiero diagnostica como se encuentra realmente una empresa, recopilando, interpretando y comparando todos los datos y acontecimientos pasados y actuales. (Baena, 2014). Este análisis se realiza utilizando el Estado de Situación Financiera, el Estado de Resultados, el Estado de flujos de Efectivo y el Estado de Cambios en el Patrimonio Neto. (Novoa, 2019; art.9, NIC1). Los estados financieros y las razones financieras son vitales para que los inversores elijan en qué empresa invertir., dado que, es la gestión de la empresa la que atrae a los inversores a través de las señales que proporcionan al mercado. (Asiri, 2015) Según Flores (2014), los estados financieros de una empresa, dan información a los usuarios de la situación financiera, del rendimiento y del flujo de efectivo en la empresa, para que ellos por su parte puedan tomar decisiones económicas. Las condiciones de mercado son cada vez más competitivas, y las actividades de la empresa están estrechamente relacionados con sus resultados financieros; por lo que, es importante seleccionar los indicadores que se utilizarán en este tipo de decisiones. (Erdogan, et al, 2015)

En el análisis financiero, los coeficientes financieros se utilizan por su simplicidad y valor adicional de la información. Estas razones analizan la tendencia de la situación financiera, Horizontalmente y verticalmente a una empresa. Las ratios financieras se clasifican en indicadores de productividad, rentabilidad, costo, liquidez, solvencia, estructura de capital e indicadores del mercado de capitales. (Mysková y Hayek, 2017: Holded, 2021, ESAN 2005). Una ratio financiera consiste en un numerador y un denominador, que relacionan dos importes financieros que pueden ser del Estado de Situación Financiera, del Estado de Resultados, o de ambos. (Faello, 2015) 
Los coeficientes de liquidez, indican si la empresa tiene capacidad para pagar sus obligaciones en los próximos doce meses del ejercicio. (Muhammad, G. et al 2019). Tenney y Malenkoski (2019) lo describen como un fondo de emergencia de fácil acceso.

\section{Las razones de liquidez más importantes son:}

1) Razón Corriente: cuya fórmula es Razón Corriente = activo corriente/pasivo corriente.

Mide la capacidad de pago de la empresa por cada sol de deuda y mientras mayor valor tenga, indica que la empresa es más sólida para sus pagos.

2) Razón de Prueba ácida: su fórmula es Prueba ácida= (activo corriente - inventario) /pasivo corriente. Mide si la empresa tiene activos corrientes que se puedan volver efectivo fácilmente para pagar sus deudas sin tener que vender su inventario.

3) Razón de caja: su fórmula es Ratio de caja: Efectivo y equivalente de efectivo/pasivo corriente. Mide el efectivo líquido que tiene la empresa para pagar sus deudas en los doce meses posteriores, cuyo resultado mínimo será 1 .

4) Razón de Capital de Trabajo: cuya fórmula es Capital de Trabajo = activo corriente pasivo corriente. Mide el capital de trabajo que posee la empresa frente a sus deudas de corto plazo. (Perú contable,2020).

Las razones de rentabilidad nos dan a saber el dinero ganado en una empresa y como se ha beneficiado con los recursos que tiene. Las razones más importantes son:

1) Ratio de rentabilidad financiera ( $\mathrm{ROE})$ : Esta ratio mide la rentabilidad generada por sus propios recursos de la empresa, calculando el beneficio neto producto de la inversión de sus accionistas.

Cuya fórmula es ROE $=$ Utilidad Neta / Activo propio * 100.

2) Ratio de rentabilidad económica (ROI): Mide el efecto de una inversión en particular y comprueba si se ha tenido ganancias.

$\mathrm{Su}$ fórmula es ROI = Utilidad antes de impuestos / Total activo $* 100$.

3) Ratio de Rentabilidad General (ROA): Mide la relación existente entre el resultado obtenido en un período y el total de los activos de una empresa. Determina la aptitud de los activos en producir beneficios.

Su fórmula es ROA $=$ Utilidad operatoria /Total activo $* 100$. Con relación a estas ratios, Rettobjaan (2020) manifiesta que, si la empresa tiene un alto ratio de liquidez y rentabilidad, reducirá la probabilidad de riesgo de quiebra, debido que la razón de liquidez demuestra la capacidad de la empresa para pagar todas sus obligaciones a corto plazo con 
el uso de sus activos corrientes, de tal manera que, si la empresa puede producir grandes activos, la empresa puede cubrir sus obligaciones.

La ratio de solvencia indica claramente si con los activos que posee la empresa se puede pagar sus deudas en el plazo indicado. Para tener solvencia el valor ideal es 1,5, si es menor la empresa no va a poder pagar sus deudas a corto plazo, pero se puede manejar la situación; y si es mayor la empresa tiene exceso de activos corrientes, y estos pierden su valor. (Perú contable, 2018). Los más usados son:

1) Ratio de Solvencia = Total Activos /Total pasivos.

2) La ratio de endeudamiento, indica porcentualmente, el tamaño de la deuda usada por la empresa para financiar sus activos corrientes y no corrientes, por cada sol de su patrimonio a corto plazo.

Cuya fórmula es Ratio de endeudamiento = Total pasivo/patrimonio neto.

3) Ratio de endeudamiento a largo plazo, mide porcentualmente las deudas de la empresa que se pagarán en el largo plazo con relación a su patrimonio.

Cuya fórmula es ELP = pasivo no corriente/patrimonio neto, a decir de Bhatia y Dhamija (2013) El apalancamiento financiero representa una señal positiva, ya que es el nexo de confianza para los futuros gerentes de la empresa.

4) Ratio de apalancamiento financiero indica el capital que se necesita para realizar inversiones específicas en la empresa.

Su fórmula es: Apalancamiento Financiero = Total activo/patrimonio neto .

De lo anteriormente mencionado, se formula las siguientes interrogantes, hipótesis y objetivos:

\section{Problema general}

- ¿Cuál es la incidencia del COVID-19 en la situación económico financiera en la Cooperación Agraria Peruana Jaén 2020?

\section{Problemas específicos}

- ¿Cuál es la incidencia de las medidas gubernamentales sociales en la situación económico financiera en la Cooperación Agraria Peruana Jaén 2020?

- ¿Cuál es la incidencia de las medidas gubernamentales económicas en la situación económico financiera en la Cooperación Agraria Peruana Jaén 2020?

- ¿Cuál es la incidencia de las ratios financieras en la situación económico financiera en la Cooperación Agraria Peruana Jaén 2020? 


\section{Hipótesis}

- La incidencia del COVID-19 en la situación económico financiera en la Cooperación Agraria Peruana Jaén 2020 es significativa.

\section{Objetivo general}

- Determinar la incidencia del COVID-19 en la situación económico financiera en la Cooperación Agraria Peruana Jaén 2020.

\section{Objetivos específicos}

- Describir la incidencia de las medidas gubernamentales sociales en la situación económico financiera en la Cooperación Agraria Peruana Jaén 2020.

- Describir la incidencia de las medidas gubernamentales económicas en la situación económico financiera en la Cooperación Agraria Peruana Jaén 2020.

- Determinar la incidencia de las ratios financieras en la situación económico financiera en la Cooperación Agraria Peruana Jaén 2020.

\section{ESTRATEGIAS METODOLÓGICAS O MATERIALES Y MÉTODOS}

\section{Tipo y diseño de investigación}

La presente investigación es de tipo aplicada, pues de acuerdo al Consejo Nacional de Ciencia, Tecnología e Innovación Tecnológica (2018) y Sánchez, et al (2018), la definen como pragmática o utilitaria que parte de la investigación básica para solucionar problemas el conocimiento y solución de problemas rápido.

De nivel correlacional, pues recolecta información sobre las variables de estudio, aspectos más importantes, sus dimensiones del problema investigado, es así que a través del estudio se determina la incidencia del COVID-19 en la situación económico financiera en la Cooperación Agraria Peruana Jaén 2020, procedimiento que fue contrastada de forma estadística (Hernández, y Mendoza, 2018).

Por lo tanto, el diseño fue no experimental, pues son estudios en los que no se manipulan las variables y solamente se observan los eventos que suceden y se los analiza; transeccional o transversal, porque recolecta información en un solo momento; y descriptivo, porque indagan la incidencia de las variables en una población, en un período de tiempo. (Hernández, y Mendoza, 2018).

\section{Esquema de diseño:}




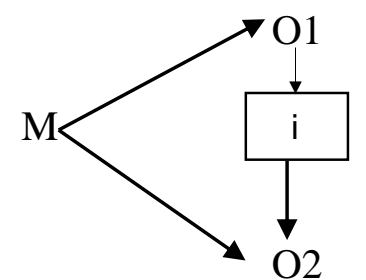

\section{Donde:}

$\mathrm{M}=$ Muestra de estudio

O1 = Covid -19

$\mathrm{O} 2$ = Situación Económico Financiera.

$\mathrm{i}=$ incidencia

\section{Población}

La población se conformó con los 5 trabajadores administrativos de la empresa, constituido por el Gerente General, Administrador, Contador, Cajero, y el responsable de Logística de la Cooperación Agraria Peruana 2020.

\section{Muestra y muestreo}

La muestra fue igual que la población, es decir 5 personas que están relacionados con las finanzas y contabilidad de la empresa

El muestreo empleado fue el no probabilístico, pues permitió seleccionar casos con las mismas características de la población, además la muestra tomada fue muy pequeña.

\section{Procedimiento}

La recolección de la información se realizó en 3 pasos, la primera se centró en la coordinación con el gerente de la Cooperación Agraria Peruana de la ciudad de Jaén, con el propósito de solicitar permiso para recolectar los datos y la información general, el segundo paso se centró en la capacitación y preparación de los encuestados en cuanto al protocolo de bioseguridad, al cuidado y medidas de protección a tomar durante la recolección de la información, el tercer paso se centró en la digitalización de la información recogida de los encuestados.

\section{Método de análisis de datos.}

Se empleó el método estadístico, mediante los programas Microsoft Excel e IBM SPSS24, con los que se elaboraron tablas y figuras para el análisis de los resultados. 


\section{A. Resultados descriptivos}

\section{Tabla 1}

Incidencia de las Medidas Gubernamentales Sociales en la situación económico financiera.

\begin{tabular}{|c|c|c|c|c|c|c|c|c|c|c|}
\hline & \multicolumn{2}{|c|}{$\mathbf{N}$} & \multicolumn{2}{|c|}{$\mathrm{Cn}$} & \multicolumn{2}{|c|}{$\overline{A v}$} & \multicolumn{2}{|c|}{$\mathrm{Cs}$} & \multicolumn{2}{|c|}{$\mathbf{S}$} \\
\hline & $\mathbf{N}$ & $\%$ & $\mathbf{n}$ & $\%$ & $\mathbf{N}$ & $\%$ & n & $\%$ & $\mathbf{n}$ & $\%$ \\
\hline $\begin{array}{l}\text { Origen del Covid }-19 \text { incide en la } \\
\text { situación económico financiera }\end{array}$ & 0 & $0 \%$ & 2 & $40 \%$ & 3 & $60 \%$ & 0 & $0 \%$ & 0 & $0 \%$ \\
\hline $\begin{array}{l}\text { Tasa de Contagio del Covid - } 19 \\
\text { incide en la situación económico } \\
\text { financiera }\end{array}$ & 0 & $0 \%$ & 4 & $80 \%$ & 1 & $20 \%$ & 0 & $0 \%$ & 0 & $0 \%$ \\
\hline $\begin{array}{l}\text { La declaratoria de } \quad \text { Emergencia } \\
\text { Sanitaria del Covid - } 1919 \text { incide en } \\
\text { la situación económico financiera }\end{array}$ & 0 & $0 \%$ & 2 & $40 \%$ & 3 & $60 \%$ & 0 & $0 \%$ & 0 & $0 \%$ \\
\hline $\begin{array}{l}\text { Número de muertos incide en la } \\
\text { situación económico financiera }\end{array}$ & 2 & $40 \%$ & 0 & $0 \%$ & 3 & $60 \%$ & 0 & $0 \%$ & 0 & $0 \%$ \\
\hline $\begin{array}{l}\text { Medidas de prevención y control } \\
\text { sanitario evitar propagación Covid - } \\
19 \text { incide en la situación económico } \\
\text { financiera }\end{array}$ & 1 & $20 \%$ & 1 & $20 \%$ & 1 & $20 \%$ & 2 & $40 \%$ & 0 & $0 \%$ \\
\hline $\begin{array}{l}\text { Medidas de prevención y control } \\
\text { sanitario evitar propagación Covid - } \\
19 \text { en los centros laborales incide en la } \\
\text { situación económico financiera }\end{array}$ & 1 & $20 \%$ & 1 & $20 \%$ & 2 & $40 \%$ & 1 & $20 \%$ & 0 & $0 \%$ \\
\hline $\begin{array}{l}\text { Declaración de emergencia nacional y } \\
\text { aislamiento social obligatorio incide } \\
\text { en la situación económico financiera }\end{array}$ & 1 & $20 \%$ & 1 & $20 \%$ & 2 & $40 \%$ & 1 & $20 \%$ & 0 & $0 \%$ \\
\hline $\begin{array}{l}\text { Restricciones en el ámbito de la } \\
\text { actividad comercial, actividades } \\
\text { culturales, establecimientos y } \\
\text { actividades recreativas, hoteles y } \\
\text { restaurantes incide en la situación } \\
\text { económico financiera }\end{array}$ & 0 & $0 \%$ & 1 & $20 \%$ & 1 & $20 \%$ & 2 & $40 \%$ & 1 & $20 \%$ \\
\hline
\end{tabular}

Se evidenció que el $60 \%$ de los trabajadores consideraron que a veces el origen del Covid - 19 incide en la situación económico financiera; asimismo, el 80\% casi nunca identificó la incidencia de la tasa de Contagio del Covid - 19; además, el $60 \%$ consideró que a veces incide la declaratoria de emergencia Sanitaria del Covid - 19 y el número de muertos; al mismo tiempo, el $40 \%$ consideró que casi siempre inciden las medidas de prevención y control sanitario para evitar propagación Covid - 19 y las restricciones en el ámbito de la actividad comercial, actividades culturales, establecimientos y actividades recreativas, hoteles y restaurantes; por último, el $40 \%$ consideró que a veces inciden las medidas de prevención y control sanitario para evitar propagación Covid - 19 en los centros laborales 
y la declaración de emergencia nacional y aislamiento social obligatorio en la situación económico financiera de la cooperación.

Tabla 2.

Incidencia de las Medidas Gubernamentales Económicas en la situación económico financiera.

\begin{tabular}{|c|c|c|c|c|c|c|c|c|c|c|}
\hline & \multicolumn{2}{|r|}{$\mathbf{N}$} & \multicolumn{2}{|c|}{$\mathrm{Cn}$} & \multicolumn{2}{|c|}{$\mathbf{A v}$} & \multicolumn{2}{|c|}{$\mathrm{Cs}$} & \multicolumn{2}{|c|}{$\mathbf{S}$} \\
\hline & n & $\%$ & n & $\%$ & n & $\%$ & $\mathrm{n}$ & $\%$ & $\mathbf{n}$ & $\%$ \\
\hline $\begin{array}{l}\text { El Subsidio del } 35 \% \text { incide en la } \\
\text { situación económico financiera }\end{array}$ & 1 & $20 \%$ & 1 & $20 \%$ & 2 & $40 \%$ & 1 & $20 \%$ & 0 & $0 \%$ \\
\hline $\begin{array}{l}\text { El } \begin{array}{l}\text { Beneficio } \\
\text { empresarial FAE }\end{array}-\text { MYPE } \text { incide } \\
\text { en la situación } \\
\text { financiera }\end{array}$ & 1 & $20 \%$ & 1 & $20 \%$ & 2 & $40 \%$ & 1 & $20 \%$ & 0 & $0 \%$ \\
\hline $\begin{array}{l}\text { El otorgamiento de crédito con } \\
\text { Programa Reactiva Perú incide en } \\
\text { la situación económico financiera }\end{array}$ & 0 & $0 \%$ & 2 & $40 \%$ & 0 & $0 \%$ & 2 & $40 \%$ & 1 & $20 \%$ \\
\hline
\end{tabular}

Se evidenció que el $40 \%$ de los trabajadores consideraron que a veces el subsidio del $35 \%$ y el beneficio del fondo empresarial FAE - MYPE inciden en la situación económico financiera; el $40 \%$ consideró que casi nunca y casi siempre el otorgamiento de crédito con programa reactiva Perú incide en la situación económico financiera de la Cooperación Agraria Peruana.

Tabla 3.

Incidencia de los Ratios Financieros en la situación económico financiera

\begin{tabular}{|c|c|c|c|c|c|c|c|c|c|c|}
\hline & \multicolumn{2}{|c|}{$\mathbf{N}$} & \multicolumn{2}{|c|}{$\mathrm{Cn}$} & \multicolumn{2}{|c|}{$\mathbf{A v}$} & \multicolumn{2}{|c|}{ Cs } & \multicolumn{2}{|c|}{$\mathbf{S}$} \\
\hline & $\mathbf{n}$ & $\%$ & $\mathbf{N}$ & $\%$ & $\mathrm{n}$ & $\%$ & $\mathrm{n}$ & $\%$ & $\mathrm{n}$ & $\%$ \\
\hline $\begin{array}{l}\text { La Razón corriente o liquidez } \\
\text { general incide en la situación } \\
\text { económico financiera }\end{array}$ & 0 & $0 \%$ & 0 & $0 \%$ & 3 & $60 \%$ & 0 & $0 \%$ & 2 & $40 \%$ \\
\hline $\begin{array}{l}\text { La Razón de Prueba ácida incide } \\
\text { en la situación económico } \\
\text { financiera }\end{array}$ & 0 & $0 \%$ & 0 & $0 \%$ & 1 & $20 \%$ & 4 & $80 \%$ & 0 & $0 \%$ \\
\hline $\begin{array}{l}\text { La Razón de efectivo incide en la } \\
\text { situación económico financiera }\end{array}$ & 0 & $0 \%$ & 0 & $0 \%$ & 1 & $20 \%$ & 2 & $40 \%$ & 2 & $40 \%$ \\
\hline $\begin{array}{l}\text { La Razón de Capital de Trabajo } \\
\text { incide en la situación económico } \\
\text { financiera }\end{array}$ & 0 & $0 \%$ & 0 & $0 \%$ & 0 & $0 \%$ & 3 & $60 \%$ & 2 & $40 \%$ \\
\hline $\begin{array}{l}\text { El Ratio de Solvencia incide en la } \\
\text { situación económico financiera. }\end{array}$ & 0 & $0 \%$ & 0 & $0 \%$ & 3 & $60 \%$ & 2 & $40 \%$ & 0 & $0 \%$ \\
\hline $\begin{array}{l}\text { El Ratio de endeudamiento incide } \\
\text { en la situación económico } \\
\text { financiera }\end{array}$ & 0 & $0 \%$ & 0 & $0 \%$ & 2 & $40 \%$ & 3 & $60 \%$ & 0 & $0 \%$ \\
\hline $\begin{array}{l}\text { El Ratio de endeudamiento a largo } \\
\text { plazo incide en la situación } \\
\text { económico financiera }\end{array}$ & 0 & $0 \%$ & 0 & $0 \%$ & 2 & $40 \%$ & 3 & $60 \%$ & 0 & $0 \%$ \\
\hline
\end{tabular}




\begin{tabular}{|c|c|c|c|c|c|c|c|c|c|c|}
\hline $\begin{array}{l}\text { El Ratio de apalancamiento } \\
\text { financiero incide en la situación } \\
\text { económico financiera }\end{array}$ & 0 & $0 \%$ & 0 & $0 \%$ & 4 & $80 \%$ & 1 & $20 \%$ & 0 & $0 \%$ \\
\hline $\begin{array}{l}\text { El Ratio de rentabilidad financiera } \\
\text { (ROE) incide en la situación } \\
\text { económico financiera. }\end{array}$ & 0 & $0 \%$ & 0 & $0 \%$ & 4 & $80 \%$ & 1 & $20 \%$ & 0 & $0 \%$ \\
\hline $\begin{array}{l}\text { El Ratio de rentabilidad } \\
\text { económica (ROI) incide en la } \\
\text { situación económico financiera }\end{array}$ & 0 & $0 \%$ & 1 & $20 \%$ & 2 & $40 \%$ & 2 & $40 \%$ & 0 & $0 \%$ \\
\hline $\begin{array}{l}\text { El Ratio de rentabilidad general } \\
\text { (ROA) incide en la situación } \\
\text { económico financiera }\end{array}$ & 0 & $0 \%$ & 0 & $0 \%$ & 3 & $60 \%$ & 0 & $0 \%$ & 2 & $40 \%$ \\
\hline
\end{tabular}

En la tabla 3 se evidenció que el 60\% de los trabajadores consideraron que a veces incide la razón corriente o liquidez general, el 80\% consideró que casi siempre incide la razón de prueba ácida y otro $40 \%$ consideró que casi siempre y siempre inciden la razón de efectivo; asimismo, el 60\% consideró que casi siempre incide la razón de capital de trabajo; también, se evidenció que el $60 \%$ de los trabajadores consideraron que a veces incide la ratio de solvencia y otro $60 \%$ consideró que inciden casi siempre la ratio de endeudamiento y la ratio de endeudamiento a largo plazo; y un $80 \%$ consideró que a veces incide la ratio de apalancamiento financiero; asimismo, se observó que, el 80\% de los trabajadores consideraron que a veces incide la ratio de rentabilidad financiero (ROE) y otro $40 \%$ consideró que a veces y casi siempre incide la ratio de rentabilidad económica (ROI); además, el 60\% consideró que incide la ratio de rentabilidad general (ROA) en la situación económico financiera de la Cooperación Agraria Peruana.

\section{Evaluación mediante Ratios Financieros}

\section{Tabla 1}

Ratio de Razón Corriente

\begin{tabular}{ll}
\hline Razón Corriente $=$ Activo corriente $/$ Pasivo corriente \\
\hline \multicolumn{1}{c}{$\mathbf{2 0 1 9}$} & \multicolumn{1}{c}{$\mathbf{2 0 2 0}$} \\
\hline $\mathrm{RC}=1,911,486 / 1,362,429$ & $\mathrm{RC}=2,843,402 / 2,188,242$ \\
$\mathrm{RC}=1.40$ & $\mathrm{RC}=1.30$ \\
\hline
\end{tabular}

Para el periodo 2019 la empresa dispuso de un Ratio de Razón Corriente de 1.40 veces, por otro lado, en el periodo 2020 dispondrá de 1.30 veces indicando que la empresa aún tiene recursos para cumplir con sus obligaciones a corto plazo. El Ratio mínimo es 1 y el óptimo es 1.5 , lo que señala que este resultado es aceptable. 


\section{Tabla 2}

Razón de Prueba Ácida

\begin{tabular}{ll}
\hline \multicolumn{2}{c}{ Razón Prueba Ácida= Activo corriente - inventarios / Pasivo corriente } \\
\hline \multicolumn{1}{c}{$\mathbf{2 0 1 9}$} & \multicolumn{1}{c}{$\mathbf{2 0 2 0}$} \\
\hline $\mathrm{RPA}=1,911,486-603,570 / 1,362,429$ & $\mathrm{RPA}=2,843,402-278,928 / 2,188,242$ \\
$\mathrm{RPA}=0.96$ & $\mathrm{RPA}=1.17$ \\
\hline
\end{tabular}

Para el periodo 2019 la empresa dispuso de una Razón de Prueba Ácida de 0.96 veces, por otro lado, en el periodo 2020 de 1.17 veces lo cual indica que no va a tener problemas para cumplir con las obligaciones de la empresa en el corto plazo.

\section{Tabla 3}

Ratio de Caja o Prueba Defensiva

\begin{tabular}{ll}
\hline \multicolumn{2}{c}{ Razón de Caja $=$ Efectivo y Equivalente de efectivo $/$ Pasivo corriente X100 } \\
\hline \multicolumn{1}{c}{2019} & \multicolumn{1}{c}{$\mathbf{2 0 2 0}$} \\
\hline $\mathrm{RC}=734,031 / 1,362,429$ & $\mathrm{RC}=267,206 / 2,188,242$ \\
$\mathrm{RC}=0.54=54 \%$ & $\mathrm{RC}=0.12=12 \%$ \\
\hline
\end{tabular}

Para el periodo 2019 la empresa dispuso de un Ratio de Caja o Prueba Defensiva de 0.54 veces, por otro lado, en el periodo 2020 de 0.12 veces lo cual indica una baja significativa a fin de pagar sus deudas en los doce meses posteriores.

\section{Tabla 4}

Ratio de Capital de Trabajo

\begin{tabular}{ll}
\hline \multicolumn{2}{c}{ Razón de Capital de Trabajo $=$ Activo Corriente - Pasivo corriente } \\
\hline \multicolumn{1}{c|}{$\mathbf{2 0 1 9}$} & \multicolumn{1}{c}{$\mathbf{2 0 2 0}$} \\
\hline $\mathrm{RCT}=1,911,486-1,362,429$ & $\mathrm{RCT}=2,843,402-2,188,242$ \\
$\mathrm{RCT}=549,057$ & $\mathrm{RCT}=655,160$ \\
\hline
\end{tabular}

Para el periodo 2019 la empresa dispuso de un capital de trabajo de S/ 549,057.00 y para el periodo 2020 dispondrá de S/ 655,160.00 produciéndose una mejora a fin de cumplir con los compromisos que origina la empresa.

\section{Tabla 5}

Ratio de Solvencia

\begin{tabular}{ll}
\hline \multicolumn{2}{c}{ Razón de Solvencia $=$ Total Activo $/$ Total Pasivo } \\
\hline \multicolumn{1}{c}{$\mathbf{2 0 1 9}$} & \multicolumn{1}{c}{$\mathbf{2 0 2 0}$} \\
\hline $\mathrm{RS}=2,045,626 / 1,362,429$ & $\mathrm{RS}=2,964,191 / 2,188,242$ \\
$\mathrm{RS}=1.50$ Veces & $\mathrm{RS}=1.35$ Veces \\
\hline
\end{tabular}


Para el periodo 2019 la empresa dispuso de un Ratio de Solvencia de 1.50 veces, por otro lado, en el periodo 2020 de 1.35 veces lo cual indica que está en el rango moderado a fín de pagar sus deudas en los doce meses posteriores. El Ratio mínimo es 1 y el óptimo 1,5 lo que señala que este resultado es aceptable.

\section{Tabla 6}

Ratio de Endeudamiento

\begin{tabular}{|c|c|}
\hline \multicolumn{2}{|c|}{ Razón de Endeudamiento = Total Pasivo $/$ Patrimonio Neto } \\
\hline 2019 & 2020 \\
\hline $\mathrm{RE}=1,362,429 / 683,197$ & $\mathrm{RE}=2,188,242 / 775,948$ \\
\hline $\mathrm{RE}=1.99$ Veces & $\mathrm{RE}=2.82$ Veces \\
\hline
\end{tabular}

Para el periodo 2019 la empresa dispuso de un Ratio de Endeudamiento de 1.99 veces, por otro lado, en el periodo 2020 de 2.82 veces lo cual indica que la Asociación tiene más deudas que patrimonio.

\section{Tabla 7}

Ratio de Endeudamiento a Largo Plazo

\begin{tabular}{ll}
\hline \multicolumn{1}{c}{ Razón de Endeudamiento $=$ Pasivo } & No Corriente $/$ Patrimonio Neto \\
\hline \multicolumn{1}{c}{$\mathbf{2 0 1 9}$} & \multicolumn{1}{c}{$\mathbf{2 0 2 0}$} \\
\hline $\mathrm{RE}=0 / 683,197$ & $\mathrm{RE}=0 / 775,948$ \\
$\mathrm{RE}=0$ Veces & $\mathrm{RE}=0$ Veces \\
\hline
\end{tabular}

Para el periodo 2019 la empresa dispuso de un Ratio de Endeudamiento a largo plazo de 0 veces, igual en el periodo 2020 de 0 veces lo cual indica que la asociación no tiene deudas a largo plazo.

\section{Tabla 8}

Ratio de Apalancamiento Financiero

\begin{tabular}{ll}
\multicolumn{1}{c}{ Razón de Apalancamiento Financiero $=$} & Total Activo $/$ Patrimonio Neto \\
\hline $\mathrm{RAF}=2,045,626 / 683,197$ & $\mathrm{2020}$ \\
$\mathrm{RAF}=2,99$ Veces & $\mathrm{RAF}=2,964,191 / 775,948$ \\
\end{tabular}

Para el periodo 2019 la empresa dispuso de un Ratio de Apalancamiento financiero de 2,99 veces, por otro lado, en el periodo 2020 de 3.82 veces lo cual indica que es rentable recurrir a la financiación ajena. 


\section{Tabla 9}

Ratio de Rentabilidad Financiera (ROE)

\begin{tabular}{ll}
\hline \multicolumn{2}{c}{ Razón de Rentabilidad Financiera $=$ Utilidad Neta $/$ Activo Propio $* \mathbf{1 0 0}$} \\
\hline \multicolumn{1}{c}{$\mathbf{2 0 1 9}$} & $\mathrm{2020}$ \\
\hline $\mathrm{ROE}=315,043 / 683,197 * 100$ & $\mathrm{ROE}=25,277 / 775,948 * 100$ \\
$\mathrm{ROE}=46,11 \%$ & \\
\hline
\end{tabular}

Para el periodo 2019 la empresa dispuso de un Ratio de Rentabilidad Financiera (ROE) de $46,11 \%$, por otro lado, en el periodo 2020 de $3.26 \%$ lo cual indica una disminución significativa a fin de pagar sus deudas en los doce meses posteriores, se considera negativo por ser menor al ROA en $11.25 \%$.

\section{Tabla 10}

Ratio de Rentabilidad Económica (ROI)

\begin{tabular}{|c|c|}
\hline \multicolumn{2}{|c|}{ Razón de Rentabilidad Económica $($ ROI $)=$ Utilidad antes de impuestos $/$ Total Activo $* 100$} \\
\hline 2019 & 2020 \\
\hline $\mathrm{ROI}=448,555 / 2,045,626 * 100$ & $\mathrm{ROI}=38,925 / 2,964,191 * 100$ \\
\hline $\mathrm{ROI}=21,92 \%$ & $\mathrm{ROI}=1,31 \%$ \\
\hline
\end{tabular}

Para el periodo 2019 la empresa dispuso de un Ratio de Rentabilidad Financiera de $21,92 \%$, por otro lado, en el periodo 2020 de $1.31 \%$ lo cual indica una disminución significativa en la capacidad de los activos para generar beneficios.

\section{Tabla 11}

Ratio de Rentabilidad General (ROA)

\begin{tabular}{ll}
\hline \multicolumn{1}{c}{$\mathbf{2 0 1 9}$} & \multicolumn{1}{c}{$\mathbf{2 0 2 0}$} \\
\hline $\mathrm{ROA}=631,052 / 2,045,626 * 100$ & $\mathrm{ROA}=430,018 / 2,964,191 * 100$ \\
$\mathrm{ROA}=30,85 \%$ & $\mathrm{ROA}=14,51 \%$
\end{tabular}

Para el periodo 2019 la empresa dispuso de un Ratio de Rentabilidad General de 30,85\%, por otro lado, en el periodo 2020 de $14.51 \%$ lo cual indica una disminución significativa del 50\% pero aun así la rentabilidad general valorada positivamente por superar el $5 \%$. 


\section{B. Prueba de normalidad}

\section{Tabla 15}

Prueba de Normalidad de los datos procesados

\begin{tabular}{lccc}
\hline & \multicolumn{3}{c}{ Shapiro-Wilk } \\
\cline { 2 - 4 } & Estadístico & gl & Sig. \\
\hline El Covid - 19 &, 842 & 5 &, 171 \\
Medidas Gubernamentales Sociales &, 880 & 5 &, 311 \\
Medidas Gubernamentales Económicas &, 958 & 5 &, 794 \\
Ratios Financieros &, 851 & 5 &, 158 \\
Situación Económico Financiera &, 851 & 5 &, 198 \\
\hline
\end{tabular}

Según se observa en la tabla 15 la prueba de normalidad, se ha trabajado con el estadístico Shapiro Wilk dado que la muestra lo conformaron 5 trabajadores, por lo que, se evidenció una significancia de 0,$171 ; 0,311 ; 0,794 ; 0,158$ y 0,198 respectivamente, para la variable el Covid - 19, dimensiones Medidas Gubernamentales Sociales, Medidas Gubernamentales Económicas, Ratios Financieros y la variable Situación Económico Financiera, siendo que todos los índices son mayores a 0,05 se determinó que mantienen una distribución normal. Por lo tanto, la prueba de hipótesis entre las variables se realizó a través del estadístico de Pearson.

\section{Prueba de hipótesis}

\section{Prueba de hipótesis general}

Tabla 12

Incidencia del Covid - 19 en la Situación Económico Financiera

\begin{tabular}{llcc}
\hline Correlaciones & & & \\
\hline & & Covid_19 & Situación_Económico_Financiera \\
\hline \multirow{2}{*}{ Covid_19 } & Correlación de & 1 &, 366 \\
& Pearson & &, 545 \\
& Sig. (bilateral) & & 5 \\
Situación_Económico_- Pearson & 5 & 1 \\
Financiera & N &, 366 & \\
& Sig. (bilateral) &, 545 & 5 \\
\hline
\end{tabular}

En la tabla 16 se observaron los resultados de la prueba Pearson, con una significancia (bilateral) de 0,545 que es mayor al valor esperado $(0,05=5 \%)$ se rechaza la hipótesis de investigación, y se acepta la hipótesis nula, la cual determina que la incidencia del COVID-19 en la situación económico financiera en la Cooperación Agraria Peruana Jaén 
2020 no es significativa, corroborándose con la correlación de Pearson de 0,366 determinando que la incidencia es positiva y baja.

\section{Prueba de hipótesis específicas:}

\subsection{Prueba de hipótesis específicas 1}

\section{Tabla 13}

Incidencia de las Medidas Gubernamentales Sociales en la Situación Económico Financiera

\begin{tabular}{|c|c|c|c|}
\hline \multicolumn{4}{|l|}{ Correlaciones } \\
\hline & & $\begin{array}{c}\text { Medidas } \\
\text { Gubernamentales } \\
\text { Sociales } \\
\end{array}$ & Situación_Económico_Financiera \\
\hline \multirow{3}{*}{$\begin{array}{l}\text { Medidas } \\
\text { Gubernamentales } \\
\text { sociales }\end{array}$} & $\begin{array}{l}\text { Correlación de } \\
\text { Pearson }\end{array}$ & 1 & ,225 \\
\hline & Sig. (bilateral) & & ,715 \\
\hline & $\mathrm{N}$ & 5 & 5 \\
\hline \multirow{3}{*}{$\begin{array}{l}\text { Situación_Económi } \\
\text { co_Financiera }\end{array}$} & $\begin{array}{l}\text { Correlación de } \\
\text { Pearson }\end{array}$ & 225 & 1 \\
\hline & Sig. (bilateral) & ,715 & \\
\hline & $\mathrm{N}$ & 5 & 5 \\
\hline
\end{tabular}

En la tabla 17 se observaron los resultados de la prueba Pearson, con una significancia (bilateral) de 0,715 que es mayor al valor esperado $(0,05=5 \%)$ se rechaza la hipótesis de investigación, y se acepta la hipótesis nula, la cual describe que la incidencia de las medidas gubernamentales sociales en la situación económico financiera en la Cooperación Agraria Peruana Jaén 2020 no es significativa, corroborándose con la correlación de Pearson de 0,225 determinando que la incidencia es positiva y baja.

\subsection{Prueba de hipótesis específicas 2.}

\section{Tabla 14}

Incidencia de las Medidas Gubernamentales Económicas en la Situación Económico Financiera

\begin{tabular}{|c|c|c|c|}
\hline \multicolumn{4}{|l|}{ Correlaciones } \\
\hline & & $\begin{array}{c}\text { Medidas } \\
\text { Gubernamentales } \\
\text { Económicas }\end{array}$ & Situación_Económico_Financiera \\
\hline \multirow{4}{*}{$\begin{array}{l}\text { Medidas } \\
\text { Económicas } \\
\text { Gubernamentales }\end{array}$} & Correlación de & 1 & ,573 \\
\hline & Pearson & & \\
\hline & Sig. (bilateral) & & ,312 \\
\hline & $\mathrm{N}$ & 5 & 5 \\
\hline \multirow[t]{3}{*}{$\begin{array}{l}\text { Situación_Económi } \\
\text { co_Financiera }\end{array}$} & $\begin{array}{l}\text { Correlación de } \\
\text { Pearson }\end{array}$ &, 573 & 1 \\
\hline & Sig. (bilateral) & 312 & \\
\hline & $\mathrm{N}$ & 5 & 5 \\
\hline
\end{tabular}


En la tabla 18 se observaron los resultados de la prueba Pearson, con una significancia (bilateral) de 0,312 que es mayor al valor esperado $(0,05=5 \%)$ se rechaza la hipótesis de investigación, y se acepta la hipótesis nula, la cual describe que la incidencia de las medidas gubernamentales económicas en la situación económico financiera en la Cooperación Agraria Peruana Jaén 2020 no es significativa, corroborándose con la correlación de Pearson de 0,573 determinando que la incidencia es positiva moderada.

\subsection{Prueba de hipótesis específicas 3.}

\section{Tabla 15}

Incidencia de los Ratios Financieros en la Situación Económico Financiera.

\begin{tabular}{llcc}
\hline Correlaciones & & & \\
\hline & & $\begin{array}{c}\text { Ratios } \\
\text { Financieros }\end{array}$ & Situación_Económico_Financiera \\
\hline Ratios Financieros & Correlación de & 1 & $1,000^{* *}$ \\
& Pearson & &, 000 \\
& Sig. (bilateral) & & 5 \\
Situacion_Económico__Correlación de & $1,000^{* * *}$ & 1 \\
Financiera & Pearson & & \\
& Sig. (bilateral) &, 000 & 5 \\
\hline
\end{tabular}

En la tabla 19 se observaron los resultados de la prueba Pearson, con una significancia (bilateral) de 0,000 que es menor al valor esperado $(0,05=5 \%)$ se acepta la hipótesis de investigación, y se rechaza la hipótesis nula, la cual evaluó que la incidencia de las ratios financieras en la situación económico financiera en la Cooperación Agraria Peruana Jaén 2020 es significativa, corroborándose con la correlación de Pearson de 1,000 que la incidencia es positiva grande y perfecta.

\section{RESULTADOS Y DISCUSIÓN}

Tras la evaluación del Covid - 19 en la Cooperación Agraria Peruana de la ciudad de Jaén, según la percepción de los trabajadores se identifica que, las medidas gubernamentales han incidido negativamente en la situación económico financiera disminuyendo las utilidades al mínimo, notándose en los indicadores de liquidez, solvencia y rentabilidad del ejercicio 2020, generando problemas en el cumplimiento de sus obligaciones a corto plazo. Respecto a ello, Chapoñan y Rivera (2020) mediante su investigación señala que la empresa obtuvo perdidas de S/ 60.000 soles a mas, causadas por interrupción de actividades emitidas por el presidente debido al COVID-19, 
causando un sobreendeudamiento en la empresa al no pagar a proveedores, trabajadores y alquileres.

Asimismo, se ha evidenciado que las medidas gubernamentales sociales, han afectado la economía de la Cooperación por la propagación rápida de la pandemia, la suspensión de actividades comerciales y el distanciamiento social obligatorio incidiendo cambios significativos en el comportamiento de los socios, porque no se permitía transportar el café hasta la Cooperación, de los trabajadores, porque tenían que cumplir con su horario laboral, proveedores porque muchos negocio tuvieron que cerrar y clientes porque no se podía cumplir con las cuotas comprometidas. Se encuentra similitud en la investigación de Vargas y Ayala (2021) donde un 73,08\% de MYPES afirman que la pandemia se propago de manera rápida, obligando a cerrar sus negocios por disposición del gobierno y afectando negativamente su crecimiento, un 78.85\% fueron afectados por la suspensión de actividades, por la forma inesperada que se dio, y la falta de preparación para esta pandemia, siendo afectados económicamente y un 75\% de los clientes de C-PROVICSA se vieron afectados con el distanciamiento social, implicando así cambios significativos en el comportamiento y la salud mental de la gran parte de estos. También en la investigación de Paulino y Zacarías (2021) evalúan que el Covid - 19 tuvo un impacto negativo en las ventas de las MYPES textiles en la Galería Gamarrita Wanka - 2020.

Respecto a las medidas gubernamentales económicas por el Covid - 19, estas incidieron negativamente en la asociación porque las actividades comerciales de compra y venta no se realizaron con normalidad, tampoco las actividades de exportación por las restricciones del gobierno, parte del personal fue suspendido en su trabajo temporalmente, y no se tenía planes de contingencias para disminuir las pérdidas, debido a la inexperiencia en estos casos extremos de pandemia, pero se pudo acceder al subsidio económico del 35\% que favoreció a 4 trabajadores, se accedió al FAE MYPE y también al Programa Reactiva Perú, con montos que permitieron cumplir con la cadena de pagos de la Cooperación y no tuviera pérdidas en el ejercicio 2020. Se encuentra similitud con la investigación de Chapoñan y Rivera (2020) donde analiza que dentro de las medidas económicas que accedió la empresa se encuentra el subsidio del 35\% con un monto total de S/ 2,695.00 que favoreció a 6 trabajadores que cumplían los requisitos del DU $\mathrm{N}^{\circ}$ 033-2020. No se accedió al FAE-MYPE porque las tasas de interés estaban muy altas y se registró en el Programa Reactiva Perú, por sus tasas de interés bajas, entre el $0.50 \%$ 
hasta el 3.60\%; pero al no tener respuesta del banco, se originaron pérdidas en el I semestre de 2020. También, con la investigación de Pérez y Tapia (2020) donde analizan que la Cooperativa Agraria Allima Cacao, Chazuta 2020, presento disminución en sus actividades económicas y financieras ante el Covid - 19, porque no se pudo vender ni comprar como en los años anteriores, tampoco se realizaron exportaciones por las restricciones del gobierno, el $80 \%$ interrumpió su trabajo temporalmente por lo que no había suficiente personal para realizar las actividades diarias, Tampoco la Cooperativa implementó planes de contingencias para disminuir las pérdidas, debido a su buena estabilidad dentro del mercado comercial.

Respecto de la aplicación de los Ratios Financieros de Liquidez, Solvencia y Rentabilidad en la Cooperación, estos disminuyeron significativamente entre el ejercicio 2019 y el 2020, por la pandemia Covid - 19. En la liquidez, la razón corriente disminuyó en un $7 \%$ de 1.40 a 1.30, la ratio de prueba ácida aumentó en $22 \%$ de 0.96 a 1.17, en la ratio de prueba defensiva disminuyó en un $78 \%$ de 0.54 a 0.12 y el capital de trabajo aumentó en un 19.33\% de 549,057 a 655,160. En la Solvencia, disminuyó de 1.50 a 1.35, la ratio de endeudamiento aumentó de 1.99 a 2.82, el Ratio de apalancamiento financiero aumentó de 2.99 a 3.82 lo que indica que es rentable recurrir a financiación externa. En cuanto a la Rentabilidad General (ROA) disminuyó de $30.85 \%$ a $14.51 \%$ pero aun así todavía es positiva por superar el 5\%, la ratio de rentabilidad económica (ROI) disminuyó de $21.92 \%$ a $1.31 \%$, indicando la disminución significativa de la capacidad de los activos en generar beneficios, y por último la ratio de rentabilidad financiera (ROE) disminuyó de $46.11 \%$ a $3.26 \%$, se considera negativo por ser menor al ROA en 11.25\%. Existe similitud con la investigación de Condori y Delgado (2020) donde se demostró con las fórmulas de las razones financieras, que la liquidez en las empresas del sector turismo del Perú, disminuyó en un 31\% por el bajo nivel de ventas originado por la suspensión de sus servicios y tener que pagar cada una de sus deudas que seguían existiendo a pesar de la crisis; la razón corriente bajó en 29\% (de 1.67 a 1.19), porque se tenían que cumplir con el pago de salarios y préstamos financieros; la liquidez severa disminuyó en $34 \%$ (de 1.55 a 1.03) por lo que vieron obligados a someter a sus trabajadores a la Suspensión perfecta de labores, reducción de sueldos y renegociación de contratos con proveedores para ampliar los periodos de pago; la razón absoluta disminuyó un $30 \%$ (de 0.94 a 0.67 ) no teniendo una diferencia relevante con el ejercicio 
2019 porque contaban con liquidez para afrontar la pandemia del Covid - 19. Por su parte, Chapoñan y Rivera (2020) determinaron que la empresa obtuvo una liquidez de 0.88 porque no prestó servicios por tres meses y una Rentabilidad negativa de $-34 \%$ que no permite cumplir con las deudas a corto plazo.

Pérez y Tapia (2020) demostraron mediante fórmulas de ratios el nivel de rentabilidad de la Cooperativa Agraria Allima Cacao, Chazuta 2020 durante el primer semestre de la pandemia en el año 2020, donde la ratio de rentabilidad sobre el patrimonio bajó de $23.86 \%$ en 2019 a $-50.14 \%$ en el 2020 , porque los accionistas no realizaron aportes, ni se compraron activos. Asimismo, la ratio rentabilidad sobre los activos bajó de $11.81 \%$ en el 2019 a $-9.57 \%$ en el 2020, por el manejo del efectivo. Por otra parte, la ratio de rentabilidad de las ventas netas, disminuyó de $3.47 \%$ en el 2019 a $-26.82 \%$ en el 2020 , porque no se desarrollaron las actividades con eficiencia, por último, la ratio de margen de utilidad bruta, disminuyó de $17.88 \%$ en el 2019 a $11.68 \%$ en el 2020 , por la falta de ventas de los productos y compras de las mismas. Concluyendo que la Cooperativa se vio afectada en gran manera por la pandemia, debido a que los resultados en los ratios del primer semestre 2020 fueron negativos, existiendo variaciones significativas.

De manera general se ha determinado que el Covid - 19 incide en la situación económico financiera de la Cooperación Agraria Peruana en el año 2020, corroborada con el coeficiente de correlación de Pearson de 0,366 determinando que la incidencia es positiva y baja, al mismo tiempo, se determina una significancia de 0,545. Resultados que son similares a Pérez y Tapia (2020) donde determina que los recursos económicos frente al Covid-19 inciden significativamente en la rentabilidad de la empresa, ya que el valor de significancia fue 0,003 , resultado menor que 0,05 , con un coeficiente de contingencia de 0.656. En efecto las deficiencias evidenciadas en las actividades económicas en su dimensión recursos económicos, incidió desfavorablemente en los índices de rentabilidad.

En definitiva, las medidas sanitarias y sociales adoptadas por el gobierno inciden en la situación económico financiera de la Cooperación Agraria Peruana en el año 2020, corroborada con el coeficiente de Pearson de 0,225 determinado que la incidencia es positiva baja, al mismo tiempo, se determina una significancia de 0,715 , aceptando la hipótesis nula la cual describe que la incidencia de las medidas gubernamentales sociales en la situación económico financiera en la Cooperación Agraria Peruana Jaén 2020 no 
es significativa; y con la incidencia de las medidas económicas adoptadas por el gobierno en la situación económico financiera de la Cooperación Agraria Peruana en el año 2020, corroborada con el coeficiente de Pearson de 0,573 y una significancia bilateral del 0,312 que es mayor al valor esperado de 0,05 rechazando la hipótesis de investigación y aceptando la hipótesis nula la cual describe que la incidencia de las medidas gubernamentales económicas en la situación económico financiera en la Cooperación Agraria Peruana Jaén 2020 no es significativa, corroborándose con la correlación de Pearson de 0,573 determinando que la incidencia es positiva moderada; y en el caso de la incidencia de los ratios financieros en la situación económico financiera de la Cooperación Agraria Peruana, tiene una correlación de Pearson de 1,000 con una significancia de 0,000 menor al valor esperado de 0,05, determina que los ratios financieros inciden de manera significativa en la situación económico financiera de la Cooperación Agraria Peruana, corroborándose con la correlación de Pearson de 1,000 determinando que la incidencia es positiva grande y perfecta. Situación que desarrolla Pérez y Tapia (2020) donde las actividades económicas frente al Covid-19 inciden significativamente en la rentabilidad de la Cooperativa Agraria Allima Cacao, Chazuta 2020, a un nivel del 95\% de confiabilidad. Los resultados de la prueba estadística Chicuadrado de Pearson fueron que el valor de significancia fue 0,003 , siendo menor que 0,05 , con un coeficiente de contingencia de 0.603 . Lo que determina que las actividades económicas inciden de manera desfavorable en la rentabilidad, ya que se evidencio que no se realizaron compras ni ventas en grandes proporciones, ni se efectuaron exportaciones, entre otros, y es por ello que los índices de rentabilidad tendieron a resultar negativo.

\section{CONCLUSIÓN O CONSIDERACIONES FINALES}

Se determinó que, el Covid - 19 incide en la Situación Económico Financiera de la Cooperación Agraria Peruana respecto al año 2020, contrastada por una significancia de 0,545 y un coeficiente de correlación de Pearson de 0,366 la cual es positiva y baja, debido a que disminuyeron las utilidades al mínimo, notándose en los indicadores de liquidez, solvencia y rentabilidad del ejercicio 2020, generando problemas en el cumplimiento de sus obligaciones a corto plazo.

Asimismo, se determinó que, las Medidas Gubernamentales Sociales inciden en la Situación Económico Financiera de la Cooperación Agraria Peruana respecto al año 2020, 
contrastada por una significancia de 0,715 y un coeficiente de correlación de Pearson de 0,225 la cual es positiva y baja, por la propagación rápida de la pandemia, la suspensión de actividades comerciales y el distanciamiento social obligatorio.

Además, se determinó que, las Medidas Gubernamentales Económicas inciden en la Situación Económico Financiera de la Cooperación Agraria Peruana respecto al año 2020, contrastada por una significancia de 0,312 y un coeficiente de correlación de Pearson de 0,573 la cual es positiva y moderada, porque se accedió al subsidio económico del 35\%, al FAE MYPE y también al Programa Reactiva Perú, con montos que permitieron cumplir con la cadena de pagos de la Cooperación y un resultado positivo en el ejercicio 2020 .

Por último, se determinó que los Ratios Financieros inciden en la Situación Económico Financiera de la Cooperación Agraria Peruana respecto al año 2020, contrastada por una significancia de 0,000 y un coeficiente de correlación de Pearson de 1,000 la cual es positiva grande y perfecta, en la liquidez, la razón corriente disminuyó en un 7\%, la ratio de prueba ácida aumentó en $22 \%$, en la Solvencia, disminuyó en 10\%, en la Rentabilidad General (ROA) disminuyó a $14.51 \%$ pero aun así todavía es positiva por superar el $5 \%$, y por último la ratio de rentabilidad financiera (ROE) disminuyó a 3.26\%, se considera negativo por ser menor al ROA en $11.25 \%$

\section{LISTA DE REFERENCIAS}

Asiri, B.K. (2015) How Investors Perceive Financial Ratios at Different Growth Opportunities and Financial Leverages. Journal of Business Studies Quarterly, 2015, $\begin{array}{lllll}\text { Volume } & 6 & \text { (3). } & \text { Pp. }\end{array}$ https://www.proquest.com/openview/a5b3884d6973bc81f9aad8c89aa9cba0/1?pqorigsite $=$ gscholar $\& \mathrm{cbl}=1056382$

Baena, D. (2014) Análisis financiero. Enfoque y proyecciones. Segunda edición. Ecoe ediciones.

Colombia. https://books.google.es/books?hl=es\&lr=\&id=1Xs5DwAAQBAJ\&oi=fnd\&pg=PP1 $\& d q=$ libros + de + analisis + financiero\&ots $=w 6 A 6 e D N y Q-\&$ sig $=\mathrm{j} 8$ suiOF Ju7lfFeVMZA7Vv6Sd-

$\mathrm{A \# v}=$ onepage $\& \mathrm{q}=$ libros $\% 20 \mathrm{de} \% 20$ analisis $\% 20$ financiero $\& \mathrm{f}=$ false

Bahnareanu, C. (2020) The Economic Impact of Covid -19 Pandemic at the Beginning of 2020. Strategic Impact. 2(75). Pp. 102-112. 
https://cssas.unap.ro/en/pdf_periodicals/si75.pdf\#page=102

Banco Pichincha (5 de febrero de 2021) Ratios de solvencia y endeudamiento que debes calcular para tu empresa [Mensaje en un blog]. https://www.pichincha.com/portal/blog/post/ratios-solvencia-endeudamiento

Bhatia, M. y Dhamija, S. (2013). Voluntary Disclosure of Financial Ratios in India. South Asian Journal of Management, Vol. 22(1), Pp. 28-49. https://www.researchgate.net/profile/Meena-

Bhatia/publication/319037922_Voluntary_Disclosure_of_Financial_Ratios_in_Indi a_M_Bhatia_S_Dhamija_South_Asian_Journal_of_Management_22_1_2849/links/5a5f0b2ea6fdcc68fa9a2405/Voluntary-Disclosure-of-Financial-Ratios-inIndia-M-Bhatia-S-Dhamija-South-Asian-Journal-of-Management-22-1-28-49.pdf

Buelvas, V. y Rodríguez, U. (2021). Manual del tesista: Los factores claves para terminar tu tesis. https://www.uvrcorrectoresdetextos.com/elmanualdeltesista.

Chapoñan, V. y Rivera, K. (2020). Medidas económicas del gobierno por el covid-19 y su impacto en la situación económica-financiera de la empresa "Transporte Lamar S.A.C.” I Semestre 2020, Nuevo Chimbote. [Tesis de Licenciatura, Universidad César Vallejo Chimbote Perú]. https://repositorio.ucv.edu.pe/bitstream/handle/20.500.12692/57582/Chapo\%c3\%b 1 an_AVS-Rivera_NKA-SD.pdf?sequence=1\&isAllowed=y

Claro, M. y García, V. (2021). “Análisis del comportamiento de los agentes económicos en ahorro, inversión y consumo frente al COVID-19 en la Bahía de la ciudad de Guayaquil, periodo 2019-2020”. [Tesis de licenciatura, Universidad de GuayaquilEcuador].

http://repositorio.ug.edu.ec/bitstream/redug/53827/1/CLARO\%20MOREIRA\%20 MAR\%c3\%8dA\%20Y\%20GARC\%c3\%8dA\%20CANCIO\%20VANESSA.pdf

Clemente, V.J. et al (2021) The impact of the COVID-19 Pandemic on Social, Health, and Economy. Sustainability, 13, Pp. 1-26. https://doi.org/10.3390/su13116314

Condori, E. y Delgado, E. (2020) "Pandemia por Covid-19 y su impacto en la liquidez de las empresas del sector turismo, Perú, 2020”, (Tesis de licenciatura), Universidad César Vallejo Lima Perú. Recuperado de https://repositorio.ucv.edu.pe/bitstream/handle/20.500.12692/58904/Condori_CEEDelgado_VE-SD.pdf?sequence $=1 \&$ isAllowed $=\mathrm{y}$ 
Consejo Nacional de Ciencia, Tecnología e Innovación Tecnológica. (2018). Reglamento de calificación, clasificación y registro de los Investigadores del sistema nacional de ciencia, tecnología e innovación tecnológica - Reglamento RENACYT. Lima, Perú: CONCYTEC.

https://portal.concytec.gob.pe/images/renacyt/reglamento_renacyt_version_final.pd $\mathrm{f}$

Diario El Peruano-Normas Legales (11 de marzo de 2020) Decreto Supremo No 0082020-SA, Decreto Supremo que declara en Emergencia Sanitaria a nivel nacional por el plazo de noventa (90) días calendario y dicta medidas de prevención y control del COVID-19. https://busquedas.elperuano.pe/download/url/decreto-supremo-quedeclara-en-emergencia-sanitaria-a-nivel-decreto-supremo-n-008-2020-sa-18639812

Diario El Peruano-Normas Legales (15 de marzo de 2020) Decreto Supremo No 0442020-PCM, Decreto Supremo que declara Estado de Emergencia Nacional por las graves circunstancias que afectan la vida de la Nación a consecuencia del brote del COVID-19. https://cdn.www.gob.pe/uploads/document/file/566448/DS044PCM_1864948-2.pdf

Diario El Peruano-Normas Legales (20 de marzo de 2020) Decreto de Urgencia No 0292020, Dictan Medidas Complementarias destinadas al Financiamiento de Micro y Pequeña Empresa y otras medidas para la reducción del Impacto del COVID-19 en la economía peruana. https://busquedas.elperuano.pe/download/url/dictan-medidascomplementarias-destinadas-al-financiamiento-decreto-de-urgencia-n-029-2020-

\section{7-1}

Diario El Peruano-Normas Legales (27 de marzo de 2020) Decreto de Urgencia No 0332020, Decreto de Urgencia que establece medidas para reducir el impacto en la economía peruana, de las disposiciones de prevención establecidas en la declaratoria de Estado de Emergencia Nacional ante los riesgos de propagación del COVID - 19. https://busquedas.elperuano.pe/download/url/decreto-de-urgencia-que-establecemedidas-para-reducir-el-im-decreto-de-urgencia-no-033-2020-1865180-1

Diario El Peruano-Normas Legales (6 de abril de 2020) Decreto Legislativo $N^{\circ} 1455$, Decreto Legislativo que crea el Programa "Reactiva Perú" para asegurar la continuidad en la cadena de pagos ante el impacto del COVID-19. 
https://busquedas.elperuano.pe/download/url/decreto-legislativo-que-crea-elprograma-reactiva-peru-par-decreto-legislativo-no-1455-1865394-1

Erdogan, et al (2015). Evaluating the Effects of Various Financial Ratios on Company Financial Performance: Application in Borsa İstanbul. Business and Economics $\begin{array}{llll}\text { Research Journal, } & \text { Volume } & \text { 35-42. }\end{array}$ https://ideas.repec.org/a/ris/buecrj/0175.html

ESAN (2015) Cinco técnicas de análisis económico-financiero para las empresas. https://www.esan.edu.pe/apuntes-empresariales/2015/08/5-tecnicas-analisiseconomico-financiero-empresas/

Faello, J. (2015) Understanding the limitations of financial ratios. Academy of Accounting and Financial Studies Journal, Volume 19(3), pp. 75-85. https://www.researchgate.net/publication/330988084_Understanding_the_limitatio ns_of_financial_ratios

Flores, J. (2016) Estados Financieros: Concordados con las NIIF y las Normas de la SMV. Primera Edición. Entrelíneas S.R. Ltda. Lima Perú. Pp. 550.\}

Hernández, et al (2020) Precios volátiles del café: covid-19 y factores fundamentales del mercado. Organización Internacional del café y el Instituto Internacional de Investigación de Políticas Alimentarias, Serie Coffee Break 2. http://www.ico.org/documents/cy2019-20/coffee-break-series-2c.pdf

Hernández-Sampieri, R. y Mendoza, C. (2018) Metodología de la Investigación: Las rutas Cuantitativa, Cualitativa y Mixta. México: McGraw W - Hill / Interamericana Editores, S.A. de CV. Recuperada de

Hinostroza, B. y Chumpitazi, A. (2020) “Análisis del impacto del Covid-19 en la liquidez y solvencia en las empresas del sector hotelero supervisadas por la SMV'. (Trabajo de Investigación). Pontificia Universidad Católica del Perú. http://tesis.pucp.edu.pe/repositorio/bitstream/handle/20.500.12404/18074/Hinostroz a\%20Flores_Chumpitazi\%20Dulanto_An\%c3\%a1lisis_impacto_de1\%20\%20Covid -19UNO.pdf? sequence $=1 \&$ isAllowed $=\mathrm{y}$

Holded (21 de mayo de 2021) Ratios Financieros: ¿qué son y qué tipos existes? [Mensaje en un blog]. https://www.holded.com/es/blog/ratios-analizar-situacion-financieraempresas 
Huayna, A. y Paucar, M. (2020) “Impacto del Covid-19 en la rentabilidad de las empresas del sector azucarero supervisadas por la SMV en el período 2020". (Trabajo de Investigación). Pontificia Universidad Católica del Perú. http://tesis.pucp.edu.pe/repositorio/bitstream/handle/20.500.12404/18829/HUAYN A_HUAMANI_PAUCAR_FIGUEROA.pdf? sequence=1\&isAllowed=y

Instituto Nacional del Cáncer (NIH) COVID-19. Diccionario de Cáncer del NCI. https://www.cancer.gov/publications/dictionaries/cancer-terms/def/covid-19

Islam, S. et al (2013) The Effects of Financial Ratios on Bankruptcy. Independent Business Review, Volume 6 (2),July 2013, Pp. 52-67.

Jaramillo, J. y Ramírez, Y. (2020)” Analizar los Impactos Económicos sobre los Ingresos de los Estados Financieros durante la Pandemia en la Empresa Calzado Rómulo Cedeño de la Ciudad de Neiva Año 2018 al 2020". [Tesis de Licenciatura, Universidad Antonio Nariño. Huila http://repositorio.uan.edu.co/bitstream/123456789/4709/3/2021_JandrodeJesusJara milloyYessicadelPilarRamirez.pdf

Junta Nacional del Café (2019) La caficultura peruana está en riesgo por bajos precios y altos costos de producción. El cafetalero. (62). https://juntadelcafe.org.pe/wpcontent/uploads/2019/04/REV-62final.pdf

Junta Nacional del Café (2020) Afiliados al año 2020. https://juntadelcafe.org.pe/socios/ Khan, et al (2021) The Economic Impact of COVID-19 from a Global Perspective. Contemporary Economics. Vol. 15. Issue 1, Pp. 64-75. DOI: 10.5709/ce.18979254.436.

Medina, A. (2021) “Auditoría de gestión durante la emergencia sanitaria por el Covid 19 en el período marzo - junio del 2020 en la asesoría contable MSN Corp.” [Tesis de Licenciatura, Universidad Técnica de Ambato, Ecuador]. https://repositorio.uta.edu.ec/bitstream/123456789/32728/1/T4992i.pdf

Mesa, L. y Rengifo, U. (2020) “La planeación y la necesidad de la liquidez en tiempos de Post Covid - 19 en el rubro restaurantes ciudad de Pucallpa 2020". [Tesis de licenciatura, Universidad Nacional de Ucayali Pucallpa - Perú]. http://repositorio.unu.edu.pe/bitstream/handle/UNU/4826/UNU_ADMINISTRACI ON_2020_T_DINORA-MEZA_URSULA-RENGIFO_BRIAN-

RODRIGUEZ.pdf?sequence=1\&isAllowed=y 
Ministerio de Economía y Finanzas (2021) Norma Internacional de Contabilidad 1: Presentación de Estados Financieros. https://www.mef.gob.pe/contenidos/conta_publ/con_nor_co/vigentes/nic/1_NIC.pd $\mathrm{f}$

Mysková, R. y Hajek, P. (2017) Comprehensive assessment of firm financial performance using financial ratios and linguistic analysis of anual reports. Journal of International studies, 10(4), pp. 96-108. Doi:10.14254/2071-8330.2017/10-4/7

Molina, O.D. (2021) "Covid-19 y su impacto en establecimientos de alojamiento en la cabecera Cantonal Jipijapa”. [Tesis de licenciatura, Universidad de Sur de ManabíEcuador].

http://repositorio.unesum.edu.ec/bitstream/53000/3234/1/Odalis\%20Molina-

Tesis.pdf

Muhammad, G. et al (2019) The Influence of Financial Ratios Analysis on the Financial Performance of Micro Small Medium Enterprises in Indonesia. Review of Integrative Business and Economics Research, Vol. 8, Supplementary Issue 4, pp. 393-400. http://buscompress.com/journal-home.html

Novoa, H.H. (2019) Elaboración Analítica de los Estados Financieros: Concordada con las NIIF y Manual para la preparación de Información Financiera -SMV. Primera edición. Instituto Pacífico S.A.C. Lima Perú. Pp. 389.

OPS-OMS (2020) Enfermedad por el Coronavirus (COVID-19). Paho.org. https://www.paho.org/es/temas/coronavirus/brote-enfermedad-por-coronaviruscovid-19

Organización Mundial de la Salud (10 de noviembre de 2020). ¿Qué es la Covid - 19? https://www.who.int/es/emergencies/diseases/novel-coronavirus-2019/questionand-answers-hub/q-a-detail/coronavirus-disease-covid-19

Ortega, et al (2021). El Covid - 19 y sus principales impactos en los Estados Financieros. Primera Edición. Lima Perú. Imprenta Editorial El Búho. P.p. 506.

Pan, W. et al (2020) COVID-19: Short-Term Influence on China's Economy Considering Different Scenarios. Global Challenges 2021, 5, 2000090 pp. 1-9. DOI: 10.1002/gch2.202000090.https://doi.org/10.1002/gch2.202000090 
Pan, W. et al (2020) The influence of COVID-19 on agricultural economy and emergency mitigation measures in China: A text mining analysis. Plos One 15(10): Pp. 1-20 DOI: e0241167. https://doi.org/10.1371/journal.pone.0241167

Paulino, M. y Zacarías, B. (2021) “COVID-19 y su influencia en el control interno de las Mypes textiles en la Galería Gamarrita Wanka - 2020”, (Trabajo de investigación). Universidad Continental Huancayo Perú. https://repositorio.continental.edu.pe/bitstream/20.500.12394/8793/1/IV_FCE_310 _TI_Paulino_Zacarias_2021.pdf

Pérez, A. (7 de junio de 2019) ¿Cuáles son los ratios de rentabilidad y cómo podemos sacarles partido? [Mensaje en un blog]. https://www.obsbusiness.school/blog/cualesson-los-ratios-de-rentabilidad-y-como-podemos-sacarles-partido

Pérez, R. y Tapia, E. (2020) “Actividades económicas frente al Covid-19 y su incidencia en la rentabilidad de la Cooperativa Agraria Allima Cacao, Chazuta 2020”, (Tesis de licenciatura), Universidad César Vallejo Tarapoto - Perú. https://repositorio.ucv.edu.pe/bitstream/handle/20.500.12692/55155/P\%c3\%a9rez_ ARH-Tapia_CES-SD.pdf?sequence=1\&isAllowed=y

Perú contable (2018) Ratios Financieros: Solvencia. [Mensaje en un blog]. https://www.perucontable.com/empresa/ratios-financieros-

solvencia/\#: :text=El\%20valor\%20ideal\%20para\%20el,no\%20tiene\%20de\%20qu \%C3\%A9\%20preocuparse.\&text=Si\%20el\%20ratio\%20de\%20solvencia\%20es\%2 0mayor\%20a\%201\%2C5,es\%20decir\%20perder\%20su\%20valor.

Perú contable (2020) Índices o ratios de Liquidez. [Mensaje en un blog]. https://www.perucontable.com/empresa/indices-o-ratios-de-liquidez/

Pinilla, J. et al (2021) The Economic Impact of the SARS-COV-2 (COVID-19) Pandemic in Spain. International Journal of Environmental Resrearch and Public Health. 18, 4708, Pp. 1-14. https://doi.org/10.3390/ijerph18094708

Rettobjaan, V. (2020) Analysis of financial ratios for predicting Bankruptcy in SMEs listed on PEFINDO25. Jurnal Manajemen \& Bisnis, Vol 19(2), September 2020. Pp. 15-22. DOI: https://doi.org/10.24123/jmb.v19i2

Ríos, Y. y Rodríguez, O. (2020) “La pandemia de la covid-19 y su afección en la situación económica financiera del Hotel Bracamonte, distrito de Huanchaco 2020”. [Tesis de licenciatura, Universidad César Vallejo Trujillo - Perú]. 
https://repositorio.ucv.edu.pe/bitstream/handle/20.500.12692/53990/Rios_LYMA-

Rodriguez_SOD-SD.pdf?sequence=1\&isAllowed=y

Ruiz, et al (2021) Stagpression: The Economic and Financial Impact of the COVID-19

Pandemic. Contemporary Economics. Vol. 15. Issue 1. Pp. 19-33. DOI: 10.5709/ce.1897-9254.433.

Sánchez, et al (2018) Manual de Términos en Investigación Científica, Tecnológica y Humanística. Primera edición. Universidad Ricardo Palma- Vicerrectorado de Investigación. Santiago de Surco- Lima Perú. file:///D:/1\%20MAESTR\%C3\%8DA\%20DE\%20TRIBUTACI\%C3\%93N\%202019 $\% 20-$

\%20UNC\%20FILIAL\%20JA\%C3\%89N/PRIMER\%20CICLO/1\%20METODOLO G\%C3\%8DA\%20DE\%20LA\%20INVESTIGACI\%C3\%93N/LIBROS\%20DE\%20 METODOLOG\%C3\%8DA\%20DE\%20LA\%20INVESTIGACI\%C3\%93N/libromanual-de-terminos-en-investigacion.pdf

Santana, P. (2021) "Incidencia financiera de la pandemia Covid - 19 en la gestión de mercaderías de la empresa TAY FU S.A. al 31 de diciembre de 2020”. [Tesis de Maestría, Universidad Politécnica Salesiana, Quito - Ecuador]. https://dspace.ups.edu.ec/bitstream/123456789/20520/1/MSQ176.pdf

Tenney, J. y Kalenkoski, Ch. (2019) Financial ratios and Financial Satisfaction: Exploring Associations Between Objetive and Subjetive Measures of Financial Well-Being among older Americans. Journal of Financial Counseling and Planning, Volume 30(2), Pp. 231-243. http://dx.doi.org/10.1891/1052-3073.30.2.231

Universidad de Lima (18 de junio de 2020) Perspectivas económicas y financieras de América latina en tiempos de pandemia. https://www.ulima.edu.pe/pregrado/economia/agenda/webinar-perspectivaseconomicas-y-financieras-de-america-latina-en-tiempos

Varona, L. y Gonzales, J.R. (2021) Dynamics of the impact of COVID-19 on the economic activity of Peru. Plos One 16(1): e0244920. https://doi.org/10.1371/journal.pone.0244920 